\title{
Dissociated backward priming effects in lexical decision and pronunciation tasks
}

\author{
TODD A. KAHAN, JAMES H. NEELY, and WENDY J. FORSYTHE \\ State University of New York, Albany, New York
}

\begin{abstract}
Backward priming was examined at 150- and 500-msec prime-target stimulus onset asynchronies (SOAs) using visually presented primes and targets in lexical decision and pronunciation tasks. Two kinds of backward relations were used: compound items for which targets and primes formed a word in the backward direction (e.g., prime: HOP; target: bell), and noncompound items for which targets and primes did not form a word but were associatively related in the backward but not the forward direction (e.g., prime: BABY; target: stork). Results showed that backward priming effects were equivalent for compounds and noncompounds. However, for lexical decisions, backward priming occurred at both SOAs, whereas for pronunciation, it occurred only at the 150-msec SOA. We discuss how this SOAdissociated backward priming effect in lexical decision and pronunciation tasks poses a serious challenge for all theories of semantic priming.
\end{abstract}

Numerous studies have examined how a single-word semantic context (called the prime) can affect the processing of a following target letter string (see Neely, 1991, for a review). To allow control over the stimulus onset asynchrony (SOA) between the prime and target, in most semantic priming experiments no overt response is required to the prime and the person's task is either to make a lexical (word/nonword) decision to the target or to pronounce it aloud, as quickly as possible. The finding that reaction times (RTs) to a target are faster when it follows a semantically or associatively related prime than when it follows an unrelated prime is referred to as semantic priming. ${ }^{1}$ This effect has generated debate as to the mechanisms that produce it.

Backward priming, first reported by Koriat (1981), is the finding that priming occurs when the target is an associate of the prime but the prime is not an associate of the target (e.g., prime: CRY; target: onion). ${ }^{2}$ Koriat observed this effect in a lexical decision task with a $650-\mathrm{msec}$ SOA. Backward priming defies the intuition that the related prime word should facilitate target processing by providing a semantic context that "sets the stage" for the target's processing. Indeed, backward priming is of considerable interest because it is not, without additional assumptions, easily explained by several current accounts of semantic priming (see Neely, 1991).

Seidenberg, Waters, Sanders, and Langer (1984) replicated and extended Koriat's (1981) results by obtaining

Portions of these data were presented at the 35 th annual meeting of the Psychonomic Society, St. Louis, MO. We thank Mike Masson, Asher Koriat, Mike Cortese, Roddy Roediger, Sharon Thompson-Schill, and two anonymous reviewers for helpful comments at various stages of this work. Correspondence should be addressed to J. H. Neely, Department of Psychology, Social Sciences 112, State University of New York, Albany, NY 12222 (e-mail: jn562@csc.aibany.edu). backward priming at a 500-msec SOA in a lexical decision task, but not in pronunciation. However, Seidenberg et al.'s backward-related items formed a compound word in the forward order but not in the backward order (e.g., prime: HOP; target: bell) and were not semantically related to each other when considered as separate words, unlike many of the noncompound word pairs (e.g., prime: WATER; target: ocean) used by Koriat (1981). In finding backward priming with these reversed compound words (which we hereafter refer to as compounds), Seidenberg et al. demonstrated that backward priming is not being produced solely by forward, nonassociative, pure semantic priming, which Fischler (1977) had previously shown can occur in the lexical decision task. (See also McRae \& Boisvert, 1998, for recent data and a review.)

Because backward priming poses an intriguing theoretical puzzle, it is surprising that it has been studied in only four published articles of which we are awareKoriat (1981), Peterson and Simpson (1989), Seidenberg et al. (1984), and Shelton and Martin (1992). ${ }^{3}$ The results and procedures of these studies, all of which used visually presented targets, are summarized in Table 1. The four independent variables represented in Table 1 are (1) the type of task (lexical decision vs. pronunciation, always manipulated between subjects), (2) the prime-target SOA (always manipulated between subjects), (3) the type of material (compounds, noncompounds, or a randomized mixture of these two item types), and (4) the prime's modality (visual or auditory). The lexical decision data are displayed in the top half of Table 1 and the pronunciation data in the bottom half. The two most important aspects of these data are as follows: (1) In the lexical decision task, backward priming occurs under all conditions and to the same degree for all SOAs. (2) In pronunciation, in contrast, backward priming occurs with an SOA $<300 \mathrm{msec}$ but does not occur at SOAs of $450-500 \mathrm{msec}$, even though backward priming effects were quite robust at SOAs of 450 
Table 1

Published Backward Priming Effects for Reaction Times (RTs, in Milliseconds) and for Percent Errors (PEs) in the Paired-Presentation Paradigm

\begin{tabular}{|c|c|c|c|c|c|c|c|}
\hline \multirow[b]{3}{*}{ Task and Stimuli } & \multirow{3}{*}{$\begin{array}{c}\text { Prime } \\
\text { Modality }\end{array}$} & \multicolumn{6}{|c|}{ Prime-Target $\mathrm{SOA}^{\mathrm{a}}$ (in $\mathrm{msec}$ ) } \\
\hline & & \multicolumn{2}{|c|}{$<300$} & \multicolumn{2}{|c|}{$450-500$} & \multicolumn{2}{|c|}{$650-750$} \\
\hline & & RT & PE & RT & $\mathrm{PE}$ & $\mathrm{RT}$ & $\mathrm{PE}$ \\
\hline \multicolumn{8}{|l|}{ Lexical Decision } \\
\hline Compounds & Visual & - & - & $+21^{*}$ & $\begin{array}{l}+0.3^{b} \\
+25^{*}\end{array}$ & $\begin{array}{l}+19^{*} \\
-1.0^{\mathrm{c}}\end{array}$ & $0.0^{\mathrm{c}}$ \\
\hline Noncompounds & Visual & - & - & - & - & $\begin{array}{l}+28^{*} \\
+43^{*}\end{array}$ & $\begin{array}{l}+2.8^{\mathrm{d}} \\
+2.4^{\mathrm{e}}\end{array}$ \\
\hline Mixed & Visual & - & - & $+37^{*}$ & $+5.0^{* \mathrm{f}}$ & - & - \\
\hline Mixed & Auditory & $+22^{*}$ & $+7.0 * \mathrm{~g}$ & $+26^{*}$ & $+2.0 \mathrm{~g}$ & - & - \\
\hline$M$ & & $+22^{*}$ & $+7.0^{*}$ & $+29 *$ & +2.7 & $+24^{*}$ & +0.6 \\
\hline \multicolumn{8}{|l|}{ Pronunciation } \\
\hline Compounds & Visu & - & - & $-7^{*}$ & $+0.0^{\mathrm{b}}$ & - & - \\
\hline Noncompounds & Visual & - & - & - & - & - & - \\
\hline Mixed & Visual & - & - & -6 & $+1.0^{\mathrm{f}}$ & - & - \\
\hline Mixed & Auditory & $+22^{*}$ & $+0.0 \mathrm{~g}$ & +7 & $+2.0 \mathrm{~g}$ & - & - \\
\hline$M$ & & $+22^{*}$ & +0.0 & -2 & +1.0 & - & - \\
\hline
\end{tabular}

Note-See also note 3 . All priming effects were computed relative to the unrelated word - prime condition. Mixed = randomized mixture of compound and noncompound items. SOA, stimulus onset asynchrony. ${ }^{*} p<.05$.

${ }^{a}$ The two SOAs for auditory primes are estimates. For the auditory primes, the target appeared either 0 or $200 \mathrm{msec}$ after prime offset.

bSeidenberg et al. (1984), Experiment 3.

cShelton and Martin (1992), Experiment 2.

${ }^{d}$ Koriat (1981), Experiment 3, first target presentation.

eKoriat (1981), Experiment 3, second target presentation.

f Peterson and Simpson (1989), Experiment 1.

gPeterson and Simpson (1989), Experiment 2.

$500 \mathrm{msec}$ in a lexical decision task tested with identical materials and procedures.

This dissociative effect of SOA on backward priming in lexical decision versus pronunciation tasks is of potential interest, since differences in priming in these two tasks have served as a crucible for evaluating theories of priming (see Neely, 1991; Neely \& Keefe, 1989). It thus becomes important to determine the generality of this task/ SOA dissociation in backward priming, since it has only been directly tested once--that is, in the Peterson and Simpson (1989) study. Moreover, one potential limitation of the generality of their dissociation is that, because their primes were auditory, the backward priming observed either for lexical decisions or for pronunciation at the short SOA could have been the result of the prime's echoic memory trace persisting beyond the target's onset (Cowan, 1984). If that were so, the observed backward "associative" priming effect could have in actuality been a temporally backward priming effect (see note 2 ). To determine whether such prime persistence is necessary for obtaining backward priming at a short SOA, the present experiment uses a visual prime, the sensory memory for which is much shorter lived than is the sensory memory for an auditory prime (Darwin, Turvey, \& Crowder, 1972; Sperling, 1960). Because Peterson and Simpson (1989) reported backward priming averaged over compounds and noncompounds and did not report item analyses, a second possible limitation in the generality of their dissociation is that backward priming at the short SOA was occurring only for compounds or only for noncompounds, and perhaps even differentially so for lexical decisions and pronunciation. Thus, although backward priming at the longer SOAs does not seem to depend on the type of backward relation between the prime and the target in the lexical decision task, it could be that backward priming at the short SOA does (see note 3 ).

In the present experiment, we examined these possibilities by testing for backward priming from a visual prime in both pronunciation and lexical decision tasks with both compounds and noncompounds at a $150-\mathrm{msec}$ SOA and at a $500-\mathrm{msec}$ SOA. If the task/SOA dissociation that Peterson and Simpson (1989) reported is general, then we should observe backward priming at both SOAs for both kinds of materials in the lexical decision task, whereas backward priming in pronunciation should occur for both kinds of materials at the short, 150 -msec, SOA and for neither kind of material at the longer, 500-msec, SOA. If the dissociation is not general, then we might observe deviations from that pattern of results. For example, if it is necessary for a sensory trace of the prime to persist past target onset for backward priming to occur at a short SOA, then we might fail to find backward priming at our 150 msec SOA in either or both tasks for compounds or noncompounds, or both (see note 3 ). 


\section{METHOD}

\section{Design}

The design was a 2 (task: lexical decision vs. pronunciation) $\times$ 2 (SOA: 150 vs. $500 \mathrm{msec}$ ) $\times 2$ (priming: backward related vs. unrelated) $\times 2$ (item type: compound vs. noncompound) mixed design. Task and SOA were between-subjects and within-items effects, priming was a within-subjects and within-items effect, and item type was a within-subjects and between-items effect.

\section{Research Participants}

A total of 220 undergraduate volunteers from the State University of New York, Albany, received credit in an introductory psychology course for their participation. Data from 28 of the 124 participants who originally performed the lexical decision task were discarded because they made more than $20 \%$ errors in any one experimental condition. Most of them had error rates in the $40 \%-50 \%$ range. Because the words should have been very familiar to the participants, these high error rates were presumably due to very low motivation. Thus, we report data from 48 people tested in each task at each SOA.

\section{Materials}

Thirty-two compounds and 32 noncompound items were used. (These materials can be obtained by e-mailing J.H.N.) Fifteen and 28 of the noncompounds and compounds, respectively, were taken from Peterson and Simpson (1989). For those noncompound pairs for which data were available in the Nelson, McEvoy, and Schreiber (1989) norms, the average probability of reporting the target given the prime was only $1 \%$ ( 28 pairs), whereas the average probability of reporting the prime given the target was $17 \%$ (26 pairs) $[t(52)=$ $5.15, p<.05]$. For those compound pairs in the Nelson et al. norms, the corresponding means were $2 \%$ (26 pairs) and $10 \%$ (20 pairs) $[t(44)=3.56, p<.05]$. Thus, the compounds and noncompounds were both asymmetrically associated, with the backward (targetprime) association being stronger than the nearly nonexistent forward (prime-target) association

Eight lists were constructed from two companion lists on the basis of each of four separate random orders of target presentation. Prime words were changed across the two companion lists so that a prime that served as a related prime for either a compound or noncompound target in one list served as an unrelated prime for that same kind of target in its companion list. Each list was preceded by 24 practice trials, 8 of which contained bidirectionally related word primes and targets and 16 of which contained word primes and nonword targets.

The experimental trials were composed of 160 word/word pairs and $224 \mathrm{word} /$ nonword pairs, randomly arranged in lists of 384 pairs. Of the 160 word/word pairs, 64 were critical items from which the data are reported: 16 each of related and unrelated compound and noncompound pairs. Finally, 96 word/word pairs were bidirectional associates so as to increase the relatedness proportion (RP, the proportion of forward related word/word pairs to the total number of word/word pairs). This was done because prior research in our lab (Neely \& Sloat, 1992) suggests that backward priming is eliminated at a long SOA unless both the RP and the probability of a nonword are high. (However, Shelton and Martin, 1992, found no effect of RP on backward priming.) The 224 word/nonword filler pairs were created by switching one letter in each of a set of 224 words, so that all nonwords remained pronounceable and were created from words that were unassociated with the word prime with which they were paired.

\section{Procedure}

In both tasks, the participant was seated approximately $60 \mathrm{~cm}$ in front of a Zenith computer monitor. Instructions, stimuli, response accuracy, and response latencies were computer controlled via MEL programming (Schneider, 1988). In the pronunciation task, re- sponses were made into a SM10A Shure headset microphone connected to the MEL response box. Instructions were displayed on the computer screen and participants were allowed as much time as needed to read them. Following instructions, the practice block of 24 trials was presented. A trial consisted of three centrally presented visual events: a $500-\mathrm{msec}$ fixation display, a 150 -msec prime, and a target. Participants were told to look at the fixation and the prime and to respond to neither. For the 500-msec SOA condition, a 350msec blank screen intervened between the prime's offset and presentation of the target, whereas for the 150 -msec SOA condition, the target immediately followed the prime's offset. The target stimuli remained on the screen for $1,500 \mathrm{msec}$, or until the participant responded, whichever came first. A 2,000-msec intertrial interval (ITI) followed each trial. Participants in the lexical decision task were told to press a button labeled "word" if the target was an English word and to press a button labeled "nonword" if it was not. The word key, the "?/" key on a keyboard located in front of them, was pressed with the right index finger, and the nonword key, the " $Z$ " key, was pressed with the left index finger. Participants in both tasks were instructed to respond as quickly and accurately as possible, and participants in the pronunciation task were told to pronounce the target aloud regardless of whether or not it was an English word. Following practice, participants were given an opportunity to ask questions before beginning the four experimental blocks, each 96 trials long. Between blocks, participants were allowed to take selfpaced breaks.

\section{RESULTS}

Only data for correct "word" responses were analyzed, and RTs falling above or below $2 S D$ from each person's mean were replaced with RTs exactly $2 S D$ above or below that mean. Fewer than $1 \%$ of all the trials underwent this trimming procedure. All effects referred to as statistically significant are associated with $p$ s $<.05$, two-tailed. Both subjects (F1) and items (F2) were treated as random factors. Mean RT data, mean error data, and prim-

Table 2

Mean Reaction Times (RTs, in Milliseconds), Mean Percent Errors (PEs), and Mean Backward Priming Effects

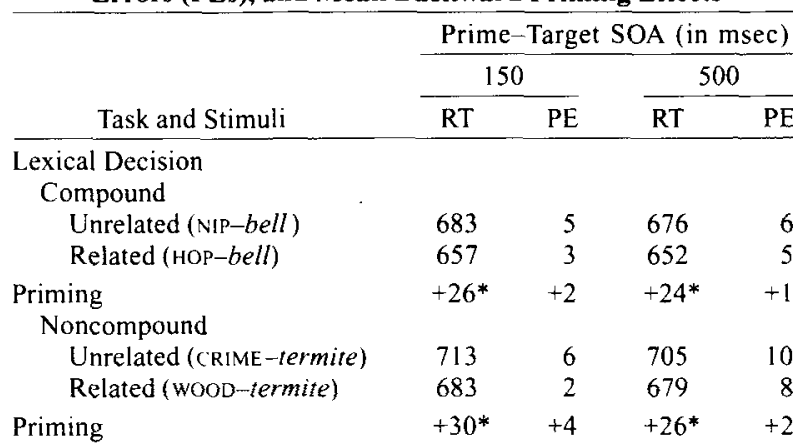

\section{Pronunciation}

Compound

Unrelated (NIP-bell)

Related ( $\mathrm{HOP}-$ bell)

Priming

Noncompound

Unrelated (CRIME-termite)

Related (WoOD-termite)

Priming

$\begin{array}{llll}641 & 4 & 631 & 3\end{array}$

$\begin{array}{llll}628 & 3 & 626 & 2\end{array}$

$+13^{*}+1 \quad+5 \quad+1$

$\begin{array}{llll}650 & 3 & 649 & 2\end{array}$

$\begin{array}{llll}637 & 3 & 645 & 2\end{array}$

$+13^{*} \quad 0 \quad+4 \quad 0$

${ }^{*} p<.05$. 
ing effects for both pronunciation and lexical decisions at both SOAs are shown in Table 2.

As shown in Table 2, the results were clear-cut. Backward priming was robust and equivalent under all conditions in the lexical decision task, ranging from 24 to $30 \mathrm{msec}$ in magnitude. In contrast, backward priming was smaller for pronunciation than for lexical decisions and was statistically significant only for the $150-\mathrm{msec}$ SOA (a 13-msec effect) and not for the 500-msec SOA (a 4.5msec effect). As for lexical decisions, the amount of priming observed at each SOA was virtually the same for compounds and noncompounds. These data show that the Peterson and Simpson (1989) results generalize across item type and across the visual versus auditory modality of the prime.

These conclusions were mostly supported by a fourfactor, mixed analysis of variance. To dispense first with the less interesting effects, a main effect of item type was found for RTs $\left[F 1(1,188)=100.87, M S_{\mathrm{e}}=840.07\right.$; $\left.F 2(1,62)=4.24, M S_{\mathrm{e}}=17,039.90\right]$, but not for errors $\left[F 1(1,188)=3.33, M S_{\mathrm{e}}=21 ; F 2(1,62)=.36, M S_{\mathrm{e}}=\right.$ 119 , both $p s>.05$ ]. This indicates that compounds yielded faster RTs (649 msec) than did noncompounds $(670 \mathrm{msec})$. This may be a frequency effect, since compound targets had a higher average frequency ( $28 /$ million) than noncompound targets (17/million), according to the Kučera and Francis (1967) word-frequency norms. This frequency difference was statistically significant $[t(62)=2.07]$. As has been shown previously (e.g., Balota \& Chumbley, 1984), this "frequency" effect was somewhat greater for lexical decisions than for pronunciation, as suggested by the task $X$ item type interaction, which was significant in the subjects analysis for both RTs $[F 1(1,188)=11.43$, $\left.M S_{\mathrm{e}}=840.07\right]$ and errors $\left[F 1(1,188)=8.45, M S_{\mathrm{e}}=21\right]$, but not in the items analysis [for RTs, $F 2(1,62)=1.66$, $M S_{\mathrm{e}}=4,827.04$; for errors, $F 2(1,62)=1.44, M S_{\mathrm{e}}=$ 76]. Finally, as is typical (see, e.g., Balota \& Chumbley, 1984), participants were significantly faster and more accurate in the pronunciation task than in the lexical decision task both for the RTs $\left[F 1(1,188)=11.29, M S_{\mathrm{e}}=\right.$ $\left.30,844.31 ; F 2(1,62)=69.27, M S_{\mathrm{e}}=4,827.04\right]$ and for errors $\left[F 1(1,188)=6.23, M S_{\mathrm{e}}=228 ; F 2(1,62)=12.29\right.$, $\left.M S_{\mathrm{e}}=76\right]$.

Of greater interest was the finding that the main effect of priming was significant for both RTs $[F 1(1,188)=$ $58.18, M S_{\mathrm{e}}=1,000.71 ; F 2(1,62)=38.05, M S_{\mathrm{e}}=$ $1,274.02]$ and errors $\left[F 1(1,188)=17.83 . M S_{\mathrm{e}}=24\right.$; $\left.F 2(1,62)=11.54, M S_{\mathrm{e}}=23\right]$, indicating that participants were both faster and more accurate to respond to backward related pairs than to unrelated pairs. However, as is almost universally found for forward priming (see Neely, 1991, for a review), our backward priming effect was numerically greater for lexical decisions than for pronunciation, yielding a significant task $\times$ priming interaction for both RTs $\left[F 1(1,188)=15.35, M S_{\mathrm{e}}=1,000.71\right.$; $\left.F 2(1,62)=16.97, M S_{\mathrm{e}}=881.39\right]$ and errors $[F 1(1,188)$ $\left.=10.27, M S_{\mathrm{e}}=24 ; F 2(1,62)=5.84, M S_{\mathrm{e}}=24\right]$.
Although the task $\times$ priming $\times$ SOA interaction did not reach conventional levels of significance (all $F \mathrm{~s}<1.6$ for both RTs and errors), we analyzed the lexical decision and pronunciation data separately to test the a priori hypothesis, based on the Peterson and Simpson (1989) data, that backward priming decreases with increasing SOA for pronunciation but is unaffected by SOA for lexical decisions. For pronunciation, the main effect of priming was significant for RTs $\left[F 1(1,94)=16.41, M S_{\mathrm{e}}=419.60\right.$; $\left.F 2(1,62)=10.50, M S_{\mathrm{e}}=456.10\right]$, but not for errors [both $F \mathrm{~s}<1]$. The crucial predicted decrease in priming at the long SOA relative to the short SOA was significant by subjects $\left[F 1(1,94)=4.32, M S_{\mathrm{e}}=419.60\right]$, but not by items $\left[F 2(1,62)=2.09, M S_{\mathrm{e}}=585.48\right]$. Moreover, the 13 -msec priming effect at the $150-\mathrm{msec}$ SOA was significantly greater than zero, both by subjects $[t 1(47)=4.82$, with 37 of 48 participants showing priming that was significant by a sign test $]$ and by items $[t 2(63)=3.18$, with 44 of 64 items showing priming that was significant by a sign test]. In contrast, the 4-msec priming effect at the 500 -msec SOA was not significantly greater than zero, either by subjects $[t 1(47)=1.27$, with only 27 of 48 participants showing priming, $p=.24$, by a one-tailed sign test $]$, or by items $[t 2(63)=1.08$, with only 35 of 64 items showing priming, $p=.27$, by a one-tailed sign test]. To lend more credence to our claim that the 4-msec priming effect at the 500-msec SOA was not different from 0 , we note that our power to detect at the 500 -msec SOA the 13-msec priming effect observed at the $150-\mathrm{msec}$ SOA was .88 , with a one-tailed significance level of .05 (see Cohen, 1988). Our ability to detect the $22-\mathrm{msec}$ effect that Peterson and Simpson (1989) reported would be greater than .99 .4 Thus, we can be reasonably sure that we would have been able to detect a priming effect comparable in magnitude to that seen at the short SOA had it been present at the 500-msec SOA. Finally, as the means for the pronunciation data clearly show, the backward priming effect and its interactive effect with SOA did not differ for the two item types (all $F_{S}<1$ ).

For lexical decisions, priming was significant for both RTs $\left[F 1(1,94)=42.17, M S_{\mathrm{e}}=1,581.82 ; F 2(1,62)=\right.$ $\left.34.51, M S_{\mathrm{e}}=1,699.31\right]$ and errors $[F 1(1,94)=17.34$, $\left.M S_{\mathrm{e}}=38 ; F 2(1,62)=11.33, M S_{\mathrm{e}}=34\right]$ and did not vary with SOA or item type (all $F_{\mathrm{s}}<1$ ). Because these priming effects are so clear, to save space we will not report the individual by-subject and by-item $F$ and sign tests for the two SOAs separately; all were significant. In short, the statistical analyses generally support the claim that backward priming effects are differentially affected by SOA in pronunciation and lexical decision tasks.

\section{DISCUSSION}

The present findings and those of Peterson and Simpson (1989) mutually reinforce each other. Though they used different modality primes, both studies show the same kind of task/SOA dissociation for backward priming. 
Specifically, backward priming occurs for both compounds and noncompounds at a short SOA but not at a moderately long SOA in pronunciation. ${ }^{5}$ In contrast, backward priming is equivalently robust for compounds and noncompounds at both of these SOAs for lexical decisions. Because backward priming at the short SOA occurs for visual as well as auditory primes, this priming does not depend on a long-lasting echoic memory trace for the prime persisting past target onset. Thus, backward priming at a short SOA can be more confidently attributed to a backward associative priming effect rather than to a temporally backward priming effect (see note 2). In addition to the dissociative effect that SOA has on backward priming, other priming dissociations have been obtained in lexical decision and pronunciation tasks. For example, mediated priming (priming from LION to stripes via TIGER) occurs for pronunciation but not for lexical decisions with procedures similar to those used here (Balota \& Lorch, 1986; but see McNamara \& Altarriba, 1988, for different results with different lexical decision procedures). With category-name primes, high-dominance exemplar targets yield more priming than low-dominance exemplar targets for pronunciation (Keefe \& Neely, 1990) but not for lexical decisions (Neely, Keefe, \& Ross, 1989). However, because of space limitations, we can now turn to only an abbreviated analysis of the questions that our backward priming dissociation raises for current theories.

Because activation spreads via directional associative links, to account for backward priming under any conditions, spreading activation theory (e.g., Anderson, 1983; McNamara, 1994) must explain how activation spreading away from the target's representation to the prime's representation facilitates target processing. Similarly, because of the (forward) directionality of an expectancy, backward priming could not be produced by an expectancybased mechanism (e.g., see C. A. Becker, 1980). Although recent neural network accounts of priming (e.g., S. Becker, Moscovitch, Behrman, \& Joordens, 1997; Masson, 1995; McRae, de Sa, \& Seidenberg, 1997; Plaut, 1995) avoid the directionality problem by accounting for backward priming through shared semantic features in the prime and target, they must explain why at long SOAs these shared semantic features affect lexical decisions but not pronunciation. Ratcliff and McKoon's (1988) compound-cue theory readily accounts for backward priming in tasks in which the familiarity of a target-prime compound can be used as a cue for making one of two binary responses, as for lexical decisions. However, it must be elaborated to explain either forward or backward priming in pronunciation. Finally, besides being able to explain the taskdissociated mediated priming and exemplar-dominance effects noted earlier (see Neely, 1991, pp. 318-320 for details), Neely and Keefe's (1989) more complex threeprocess theory can also account for why at a long SOA, backward priming occurs for lexical decisions but not pronunciation. It can do so because a "word" response in the lexical decision task is facilitated whenever a retrospec- tive semantic matching mechanism finds a relation between the target and the prime, which it can do through the backward association. However, this semantic matching mechanism is assumed to operate for lexical decisions only at long SOAs (see Neely \& Keefe, 1989, p. 218) and never in pronunciation. (This is assumed because knowledge that the target is related vs. unrelated to the prime provides information about the likelihood the target is a word or nonword, but it provides no information as to how it is pronounced.) Thus, semantic matching cannot explain backward priming in either task at a short SOA. Nor can the Neely-Keefe theory be saved by an appeal to the operation of its other two processes, spreading activation and expectancy. As noted earlier, neither of these mechanisms can readily account for backward priming under any circumstances.

In closing, we believe that the present findings and those presented in Table 1 provide a convincing case that backward priming effects are empirically robust. Thus, we hope that backward priming effects will be more systematically investigated so that they can assume the central role in future semantic priming research that we believe is warranted, given their counterintuitive nature and the challenge they pose to current theorizing.

\section{REFERENCES}

ANDERSON, J. R. (1983). The architecture of cognition. Cambridge, MA: Harvard University Press.

Balota, D. A., \& Chumbley, J. I. (1984). Are lexical decisions a good measure of lexical access? The role of word frequency in the neglected decision stage. Journal of Experimental Psychology: Human Perception \& Performance, 10, 340-357.

BalOTA, D. A., \& LoRCH, R. F. (1986). Depth of automatic spreading activation: Mediated priming effects in pronunciation but not in lexical decision. Journal of Experimental Psychology: Learning, Memory, \& Cognition, 12, 336-345.

BECKER, C. A. (1980). Semantic context effects in visual word recognition: An analysis of semantic strategies. Memory \& Cognition, 8, 493-512.

Becker, S., Moscovitch, M., Behrman, M., \& Joordens, S. (1997). Long-term semantic priming: A computational account and empirical evidence. Journal of Experimental Psychology: Learning, Memory, \& Cognition, 23, 1059-1082.

Chwilla, D. J., Hagoort, P., \& Brown, C. M. (1998). The mechanism underlying backward priming in a lexical decision task: Spreading activation versus semantic matching. Quarterly Journal of Experimental Psychology, 51A, 531-568.

COHEN, J. (1988). Statistical power analysis for the behavioral sciences (2nd ed.). Hillsdale, NJ: Erlbaum.

Cowan, N. (1984). On short and long auditory stores. Psychological Bulletin, 96, 34l-370.

Darwin, C. J., Turvey, M. T., \& Crowder, R. G. (1972). An auditory analogue of the Sperling partial report procedure: Evidence for brief auditory storage. Cognitive Psychology, 3, 255-267.

FISCHLER, I. (1977). Semantic facilitation without association in a lexical decision task. Memory \& Cognition, 5, 335-339.

KeEFE, D. E., \& NeELY, J. H. (1990). Semantic priming in the pronunciation task: The role of prospective prime-generated expectancies. Memory \& Cognition, 18, 289-298.

Kiger, J. I., \& Glass, A. L. (1983). The facilitation of lexical decisions by a prime occurring after the target. Memory \& Cognition, 11, 356365.

KORIAT, A. (1981). Semantic facilitation in lexical decision as a function of prime-target association. Memory \& Cognition, 9, 53-65. 
KuČERA, H., \& FRANCIS, W. N. (1967). Computational analysis of present day American English. Providence, RI: Brown University Press.

MASson, M. E. J. (1995). A distributed memory model of semantic priming. Journal of Experimental Psychology: Learning, Memory, \& Cognition, 21, 3-23.

MCNamara, T. P. (1994). Theories of priming; II. Types of primes. Journal of Experimental Psychology: Learning, Memory, \& Cognition, 20, 507-520.

MCNamara, T. P., \& Altarriba, J. (1988). Depth of spreading activation revisited: Semantic mediated priming occurs in lexical decisions. Journal of Memory \& Language, 27, 545-559.

MCRAe K., \& BoISVERT, S. (1998). Automatic semantic similarity priming. Journal of Experimental Psychology: Learning, Memory, \& Cognition, 24, 558-572.

MCRAE, K., DE SA, V., \& Seidenberg, M. S. (1997). On the nature and scope of featural representations of word meaning. Journal of Experimental Psychology: General, 126, 99-130.

NeELY, J. H. (1991). Semantic priming effects in visual word recognition: A selective review of current findings and theories. In D. Besner \& G. W. Humphreys (Eds.), Basic processing in reading: Visual word recognition (pp. 264-336). Hillsdale, NJ: Erlbaum.

Neely, J. H., \& KeEfE, D. E. (1989). Semantic context effects on visual word processing: A hybrid prospective/retrospective processing theory. In G. H. Bower (Ed.), The psychology of learning and motivation: Advances in research and theory (Vol. 24, pp. 207-248). New York: Academic Press.

Neely, J. H., Keefe, D. E., \& Ross, K. (1989). Semantic priming in the lexical decision task: Roles of prospective prime-generated expectancies and retrospective semantic matching. Journal of Experimental Psychology: Learning, Memory, \& Cognition, 15, 1003-1019.

Neely, J. H., \& SloAT, J. (1992, November). Dissociative mediated, backward and forward priming for lexical decisions. Paper presented at the 33rd annual meeting of the Psychonomic Society, St. Louis.

Nelson, D. L., McEvoy, C. L., \& Schreiber, T. (1989). The University of South Florida word, rhyme and word fragment norms. Unpublished manuscript.

Peterson, R. R., \& Simpson, G. B. (1989). The effect of backward priming on word recognition in single-word and sentence contexts. Journal of Experimental Psychology: Learning, Memory, \& Cognition, $15,1020-1032$.

Plaut, D. C. (1995). Semantic and associative priming in a distributed attractor network. Proceedings of the Seventeenth Annual Conference of the Cognitive Science Society, 17, 37-42.

RATCLIFF, R., \& MCKoON, G. (1988). A retrieval theory of priming in memory. Psychological Review, 95, 385-408.

SCHNEIDER, W. (1988). Microexperimental laboratory: An integrated system for IBM PC compatibles. Behavioral Research Methods, Instruments, \& Computers, 20, 206-217.

Seidenkerg, M. S., Waters, G. S., Sanders, M., \& Langer, P. (1984). Pre- and postlexical loci of contextual effects on word recognition. Memory \& Cognition, 12, 315-328.

Shelton, J. R., \& MARTIN, R. C. (1992). How semantic is automatic semantic priming? Journal of Experimental Psychology: Learning, Memory, \& Cognition, 18, 1191-1210.

SPERLING, G. (1960). The information available in brief visual presentations. Psychological Monographs, 74 (Whole No. 48).

Thompson-Schill, S. L., KurTz, K. J., \& Gabrieli, J. D. E. (1998). Effects of semantic and associative relatedness on automatic priming. Journal of Memory \& Language, 38, 440-458.

\section{NOTES}

1. We use semantic priming as a generic term to refer to semantic or associative priming.
2. Associative backward priming should be distinguished from temporally backward priming (see, e.g., Kiger \& Glass, 1983), in which the presentation of the prime ONION, which has a forward association to the target cry, can actually lag behind the presentation of that target by $65 \mathrm{msec}$ and still yield priming.

3. Shelton and Martin (1992, Experiment 2) failed to find backward priming for lexical decisions when a responded-to target served as a "prime" for the next target. But they also failed to find forward priming with the same items. After our article was in press, Chwilla, Hagoort, and Brown (1998) and Thompson-Schill, Kurtz, and Gabrieli (1998) reported additional backward priming studies. With visual primes, Thompson-Schill et al. found equivalent 17 - to 25 -msec priming effects for lexical decisions whether noncompound primes and targets were presented in the forward or backward direction with a 250-msec SOA. For pronunciation again with a $250-\mathrm{msec} S \mathrm{SOA}$, for semantically related noncompounds they found significant 12 -msec priming effects in both the forward and the backward directions, whereas for their semantically unrelated compounds, they found neither backward nor forward priming. Chwilla et al. used auditory primes, prime-target interstimulus intervals (ISIs) of 0 or $500 \mathrm{msec}$, and compounds and noncompounds in a lexical decision task. Their main findings were that comparable backward priming effects of 22-35 msec occurred for the compounds and noncompounds at both ISIs.

4. A 13-msec priming effect yields a Cohen's (1988) $d$ of .579, using the error term for the 500-msec SOA priming effect, which was larger than that for the 150-msec SOA, thereby yielding a lower $d$, which lowers our power. Thus, we are being conservative. For comparison purposes, we note that for the lexical decision task, the priming effects at each SOA, collapsed across items, each had a Cohen's $d>.617$.

5. Using the same compound and noncompound items and short SOA as in the present experiment, we found forward priming effects quite comparable to our backward priming effects for both lexical decisions and pronunciation. This replicates and extends Thompson-Schill et al.'s (1998) equivalent forward and backward priming effects for lexical decisions with noncompounds at a short SOA. However, our equivalent backward priming effects for compounds and noncompounds at a short SOA in pronunciation seem to conflict with Thompson-Schill et al.'s observing backward priming for noncompounds but not for compounds. One possible reason for this "conflict" is that for their 18 noncompounds, the target-to-prime associative strength averaged only .02, whereas for their 18 compounds it averaged .41. For our 32 pairs of each type, these two values were much closer (i.e., 10 and .17 , respectively). Hence, we conclude that an associative strength of .02 will not yield backward (or forward) priming in pronunciation, whereas associative strengths in the range of .10-.41 produce backward priming effects of 12-13 $\mathrm{msec}$, whether or not primes and targets are semantically related. We conclude this because our compounds and noncompounds yielded backward priming even though semantic similarity ratings indicated that they were virtually unrelated (i.e., on a 7-point scale, they received mean ratings of 1.92 and 2.18 , respectively). In contrast to ThompsonSchill et al.'s and our lexical decision results, Chwilla et al. (1998) observed a larger forward $(61-\mathrm{msec})$ than backward $(27-\mathrm{msec})$ priming effect or their noncompounds (though they did find comparable 25- and 29-msec forward and backward priming effects for their compounds, as we did). These conflicting results for noncompounds are difficult to interpret, since Chwilla et al. did not provide the forward and backward associative strengths for each of their unidirectionally related primetarget pairings.
(Manuscript received October 17, 1997; revision accepted for publication April 7, 1998.) 